\title{
Expression of Nef from unintegrated HIV-1 DNA downregulates cell surface CXCR4 and CCR5 on T-lymphocytes
}

\author{
Richard D Sloan', Daniel A Donahue 1,2, Björn D Kuhl1,3, Tamara Bar-Magen¹ and Mark A Wainberg*1,2,3
}

\begin{abstract}
Background: Transcription of HIV-1 cDNA prior to, or in the absence of, integration leads to synthesis of all classes of viral RNA transcripts. Yet only a limited range of viral proteins, including Nef, are translated in this context. Nef expression from unintegrated HIV-1 DNA has been shown to reduce cell surface CD4 levels in T-cells. We wished to determine whether Nef expressed from unintegrated DNA was also able to downregulate the chemokine coreceptors CXCR4 and CCR5.

Viral integration was blocked through use of an inactive integrase or by using the integrase inhibitor raltegravir. Infected cells bearing unintegrated DNA were assayed by flow cytometry in the GFP reporter cell line, Rev-CEM, for cell surface levels of CD4, CXCR4 and CCR5.

Results: In cells bearing only unintegrated HIV-1 DNA, we found that surface levels of CXCR4 were significantly reduced, while levels of CCR5 were also diminished, but not to the extent of CXCR4. We also confirmed the downregulation of CD4. Similar patterns of results were obtained with both integrase-deficient virus or with wild-type infections of cells treated with raltegravir. The Alu-HIV qPCR assay that we used for detection of proviral DNA did not detect any integrated viral DNA.

Conclusions: Our results demonstrate that Nef can be expressed from unintegrated DNA at functionally relevant levels and suggest a role for Nef in downregulation of CXCR4 and CCR5. These findings may help to explain how downregulation of CXCR4, CCR5 and CD4 might restrict superinfection and/or prevent signal transduction involving HIV-1 infected cells.
\end{abstract}

\section{Background}

Integration of the reverse transcribed HIV-1 genome into host cell chromatin is one of the defining features of retroviral replication and is mediated by the virally encoded integrase enzyme. During natural infections, unintegrated forms of HIV-1 cDNA can be detected in abundance in vivo [1-5] and in great excess relative to integrated DNA, despite normal integrase function $[1,5]$. Such unintegrated DNA can be found in three forms: linear cDNA that is the precursor to integrated proviral DNA, and 1- and 2-LTR circles that are the products of non-homologous end joining, autointegration, or recombination of linear cDNAs [6-8].

* Correspondence: mark.wainberg@mcgill.ca

${ }^{1}$ McGill University AIDS Centre, Lady Davis Institute, Jewish General Hospital, Montréal, QC, Canada

Full list of author information is available at the end of the article
Although HIV-1 unintegrated DNA cannot itself support viral replication $[9,10]$, it is transcriptionally active resulting in all classes of viral transcripts $[8,11,12]$. Translation of the early viral gene products such as Nef $[13,14]$, Tat [10,15-17] and Rev [11] from viral mRNA of unintegrated DNA origin has been well documented; however, a key limitation in translation of late transcripts is low levels of Rev produced by unintegrated templates [11].

A detailed study of transcription using Rev-CEM cells, a CEM-SS derived cell line that had been transduced with a Rev and Tat dependent GFP expression vector [18], thereby allowing GFP analysis of infected cells [19], showed them to be permissive for transcription from unintegrated templates to approximately $70 \%$ of wildtype (wt) levels [20]. Earlier studies, using the Tat induced HeLa-CD4-LTR- $\beta$-galactosidase cell line, suggested that 
unintegrated transcription occurred to about $10 \%$ of wild type levels [16]. Other work identified a viral RNA transcript arising from across the LTR-LTR junction of 2-LTR circles [21], although its biological function, if any, remains undefined. Initial transcription from unintegrated DNA appears to be mediated by virally imported $\mathrm{Vpr}$, as the presence of $\mathrm{Vpr}$ increased transcription from unintegrated DNA templates by 10-20 fold, and this process was found to be independent of Tat $[8,22]$.

Although unintegrated DNA can be transcribed, it possesses no origin of replication and so is not maintained upon cell division. Therefore, the stability of unintegrated DNA in dividing cells is governed by the rate of cell division [23,24]. Insertion of an SV40 origin of replication into integrase-defective HIV-1 molecular clones or lentiviral vector genomes allowed the maintenance and transcription of unintegrated DNA in dividing cell populations $[25,26]$. It has also been shown that unintegrated DNA is stable in growth-arrested T-cells for 5-7 days $[23,27,28]$. Non-dividing macrophages were shown to contain unintegrated DNA for up to 21 days post infection, and transcription of a viral-borne luciferase reporter gene was detectable throughout [29]. Further work demonstrated that multiple unintegrated DNA forms were present in macrophages for up to 30 days post-infection, with viral RNA transcripts and Nef being detectable during this period in a manner that correlated with altered levels of cytokine expression [12].

Nef synthesized from unintegrated DNA has also been linked to the downregulation of cell surface CD4 in primary CD4+ T-lymphocytes [14]. This was confirmed in the SupT1 cell line, in which cell surface CD4 downregulation by Nef of unintegrated DNA origin was shown to be dependent on Vpr-mediated Nef expression [8]. In other studies, pre-integration translation of Nef and Tat was shown to increase the activation state of resting $\mathrm{T}$ lymphocytes, thereby rendering them more amenable to productive infection [13].

The expression of early gene products from unintegrated DNA seems to be a natural feature of the HIV-1 replication cycle [30,31]. In addition, the use of integrase strand transfer inhibitors (INSTIs), such as raltegravir, also leads to elevated levels of unintegrated HIV-1 DNA $[32,33]$. Unintegrated DNA derived from integrationcompetent virus blocked by INSTIs shows the same pattern of transcription as preintegrated virus or integrasedeficient virus [11].

When integration does occur, Nef-mediated downregulation of each of cell surface CD4 and the CXCR4 $[34,35]$ and CCR5 [36] coreceptors has the benefit of restricting superinfection. This may protect the virus within the cell from cellular toxicities associated with superinfection, due to over-accumulation of unintegrated HIV genomes [37,38]. Additionally, downregulation of
CD4, CXCR4 and CCR5 may reduce signaling via these receptors, which might otherwise trigger apoptosis, modulate viral transcription, and alter cellular chemotaxis in infected cells $[39,40]$.

Downregulation of cell surface CD4 by Nef in primary CD4+ T-cells by unintegrated DNA is well established $[8,14]$. We now show that Nef derived from unintegrated DNA can also downregulate cell surface CXCR4 and CCR5.

\section{Results}

\section{Nef is expressed from unintegrated DNA}

We first sought to confirm that we could identify the expression of Nef in infections in which integration had not occurred [13]. Using an Alu-HIV qPCR for integrated provirus, levels of integration were expressed relative to those measured from infections using virus with a wildtype integrase at $72 \mathrm{~h}$ post infection. Neither infections with integrase deficient virus, bearing the D116N mutation, or wild-type integrase in the presence of $1 \mu \mathrm{M}$ raltegravir, displayed measurable integration, i.e. the signal discernable from unintegrated cDNA was greater than that for the Alu-HIV amplification (Figure 1A).

Expression of Nef was analyzed by Western blot. In the absence of integration, i.e. infection with either integrasedeficient $\mathrm{D} 116 \mathrm{~N}$ virus or with wt virus in the presence of raltegravir, Nef expression still occurred at readily detectable levels (Figure 1B), thus confirming the translation of Nef from unintegrated DNA templates. Additionally, we confirmed that the introduction of two stop codons in the first three codons of the Nef gene was sufficient to prevent Nef synthesis

\section{Integrated virus downregulates cell surface CXCR4, CCR5 and CD4 expression on Rev-CEM cells}

The Rev-CEM cell line was derived by transducing the Rev and Tat dependent GFP vector pNL-RRE(SA) [18] into CEM-SS cells, resulting in a CXCR4-and CCR5bearing cell line that expresses GFP in response to the simultaneous presence of Tat and Rev [19]. Downregulation of CD4, CXCR4 and CCR 5 by Nef is well established in the context of replication competent viruses [34-36]. In order to confirm that the Rev-CEM cell line was suitable for the study of Nef-mediated downregulation of cell surface receptors from cells bearing unintegrated viral DNA only, we first needed to confirm that Nef-mediated receptor downregulation was measurable following viral integration.

Infected cells (i.e. GFP positive) were assayed by flow cytometry for cell surface expression of CD4, CXCR4 and CCR5 (Figure 2). Potent downregulation of CD4 by Nef was shown to occur, with cell surface levels being only $\approx 5 \%$ of those seen with $\Delta$-nef viruses $(\mathrm{p}<0.001)$ The CXCR4 coreceptor was also downregulated by Nef, to 


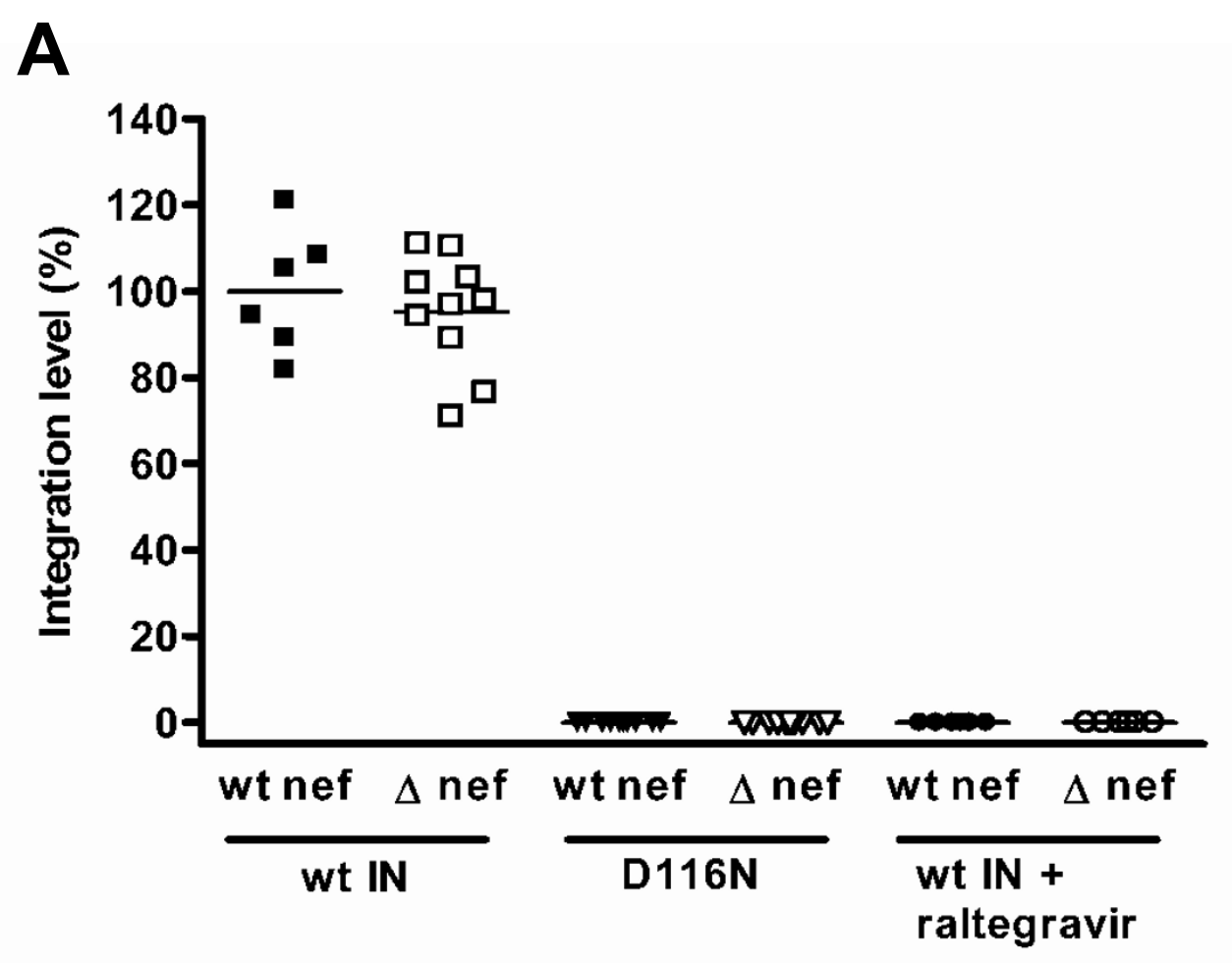

B

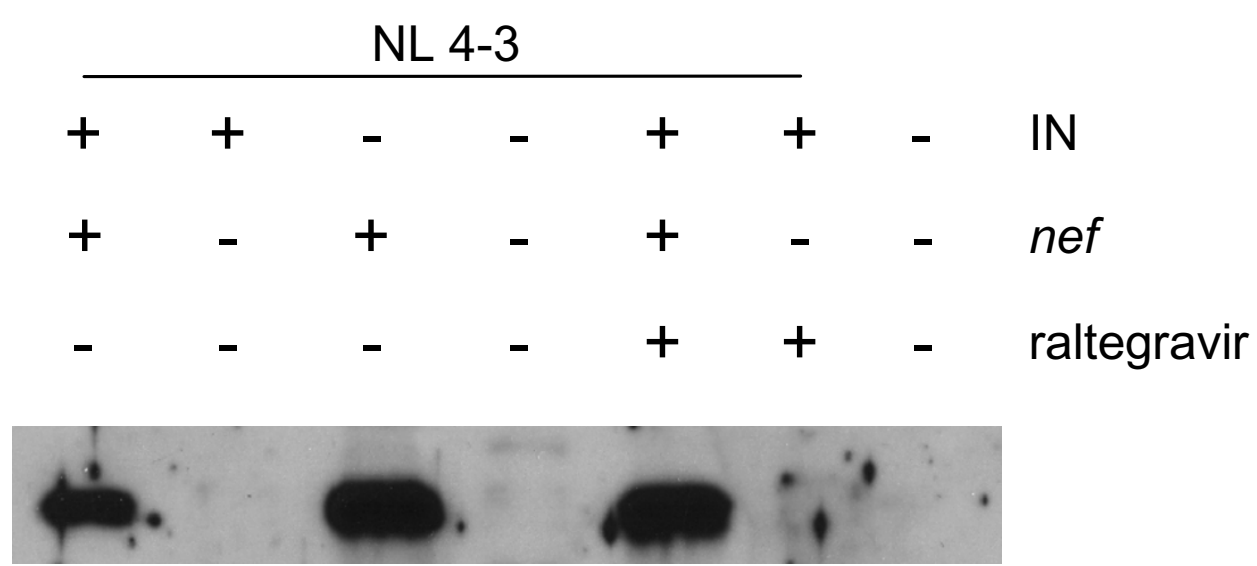

Figure 1 Nef expression in the absence of integration. A. Viral integration was measured by an Alu-HIV qPCR assay for provirus. Cells were infected with wild-type (wt) virus or D1 16N integrase-containing virus bearing either wt nef or $\Delta$-nef mutations. Repeat infections were also performed for wt integrase virus in the presence of $1 \mu \mathrm{M}$ raltegravir. At $72 \mathrm{~h}$ post-infection, DNA was extracted and qPCR analysis was performed. Results were expressed relative to those obtained with wt virus (levels of expression set at 100\%). B. Expression of Nef was confirmed by Western blot analysis of lysates from infections with wt virus (IN +) or D116N integrase-containing virus (IN -), bearing either wt nef (nef + ) or $\Delta$-nef (nef-) mutations. Repeat infections were also performed for wt integrase virus in the presence of $1 \mu \mathrm{M}$ raltegravir, a concentration shown to be completely inhibitory to integration. 


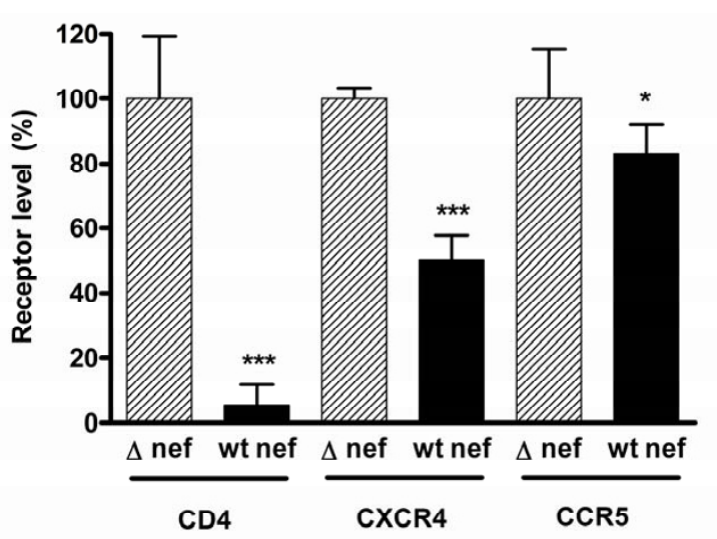

Figure 2 Nef mediated downregulation of CXCR4, CCR5 and CD4 by integrating virus. Infected (GFP positive) cells were analyzed relative to uninfected cells for cell surface CD4, CXCR4 and CCR5 after infection with wt integrase-containing virus, either wt nef or a $\triangle$-nef mutation. The results of geometric means of fluorescence for each receptor are expressed relative to $\Delta$-nef virus infection receptor levels. Results are from 3-5 independent experiments, each with two replicate infections. Error bars indicate standard deviations. For each receptor, statistical comparisons between wt nef and $\Delta$-nef were performed by two-tailed unpaired $t$-tests, $p<0.001\left(^{* *}\right) p<0.05\left(^{*}\right)$

below $50 \%$ of levels attained with the $\Delta$-nef virus (p < 0.001 ), whereas CCR5 downregulation was less, i.e. $\approx 83 \%$ of $\Delta$-nef levels $(\mathrm{p}=0.04)$.

\section{Integration deficient $\mathrm{D} 116 \mathrm{~N}$ virus downregulates cell surface CXCR4, CCR5 and CD4 expression}

Having established the suitability of the Rev-CEM cell line to measure Nef-mediated downregulation, we next wished to study integrase-deficient virus, taking advantage of the capacity of unintegrated DNA to express Tat and Rev and thereby induce GFP expression [20]. Introduction of the D116N mutation into the integrase domain renders integrase inactive, and so cells infected with such virus will bear unintegrated viral DNA only [17]. Detection by Rev-CEM cells was sensitive for the detection of unintegrated infections by flow cytometry. With integrating virus, the infection rate inferred from GFP expression was typically $10 \%$, and for integrase deficient virus typically $7 \%$ of the total population studied.

Infected cells were measured by flow cytometry for cell surface expression of CD4, CXCR4 and CCR5. A pattern of downregulation, similar to that of integrating virus was observed. These findings confirm that Nef derived from unintegrated HIV-1 DNA can downregulate cell surface CD4 to levels $\approx 11 \%$ of those attained with $\Delta$-nef virus (p $<0.001$ ) (Figure 3). As the data were normalized to internal controls, direct comparisons between integrating vs. non-integrating viruses were not made.
We have also shown that Nef expressed from unintegrated DNA also diminished levels of expression of CXCR 4 to $\approx 42 \%$ of those attained with $\Delta$-nef virus, ( $<<$ 0.001 ). In contrast, downregulation of CCR5 in the same system only occurred to a level of $\approx 80 \%$ of that seen with the $\Delta$-nef virus $(\mathrm{p}<0.02)$.

\section{Integration competent virus downregulates cell surface CXCR4, CCR5 and CD4 expression in the presence of inhibitory concentrations of raltegravir}

Having established that integrase-deficient virus could express Nef and downregulate levels of expression of entry receptors (Figure 3), we next wished to establish whether such down-modulation would also occur in the presence of an INSTI such as raltegravir. Previous work had established that $1 \mu \mathrm{M}$ of raltegravir was sufficient to prevent measurable integration in the Rev-CEM cell line by qPCR for proviral DNA (Figure 1A). We therefore performed a series of infections with wt nef and $\Delta$-nef virus to determine patterns of receptor downregulation in the presence of raltegravir.

Similar results to those for integrase-deficient virus were obtained (Figure 4), with cell surface levels of CD4 being reduced to $17 \%$ of levels attained with wild-type $\Delta$ nef virus $(\mathrm{p}<0.001)$. CXCR4 and CCR5 levels were reduced to $60 \%$ and $79 \%$ of those attained with $\Delta$-Nef virus $(\mathrm{p}<0.001$ and $\mathrm{p}=0.03$, respectively). Direct comparisons between integrase-deficient and integrase competent viruses in the pressure of raltegravir were not made, as the experiment was internally controlled.

Finally, the results of Figure 4 show that there was no direct effect of raltegravir on expression of any of CD4, CXCR4 or CCR5 in this system.

\section{Discussion}

We herein provide the first evidence of chemokine coreceptor downregulation mediated by Nef derived from unintegrated DNA. In addition, we confirm the findings of other groups that Nef expressed from unintegrated DNA can downregulate cell surface CD4 $[8,14]$. It may not be possible to make direct comparisons between our and other studies, due to different methods of flow cytometry employed.

In our studies, levels of downregulation of Nef-mediated CXCR4 derived from unintegrated DNA correlated well with results obtained in productive infection and are also in agreement with the finding that such downregulation occurs to a lesser extent than is seen for CD4 $[34,35]$. Although we observed a slightly lesser degree of downregulation of CCR 5 by Nef from unintegrated DNA than has been reported for productive infection of activated primary human peripheral blood lymphocytes, our results are broadly consistent with the $\approx 25 \%$ downregu- 
A
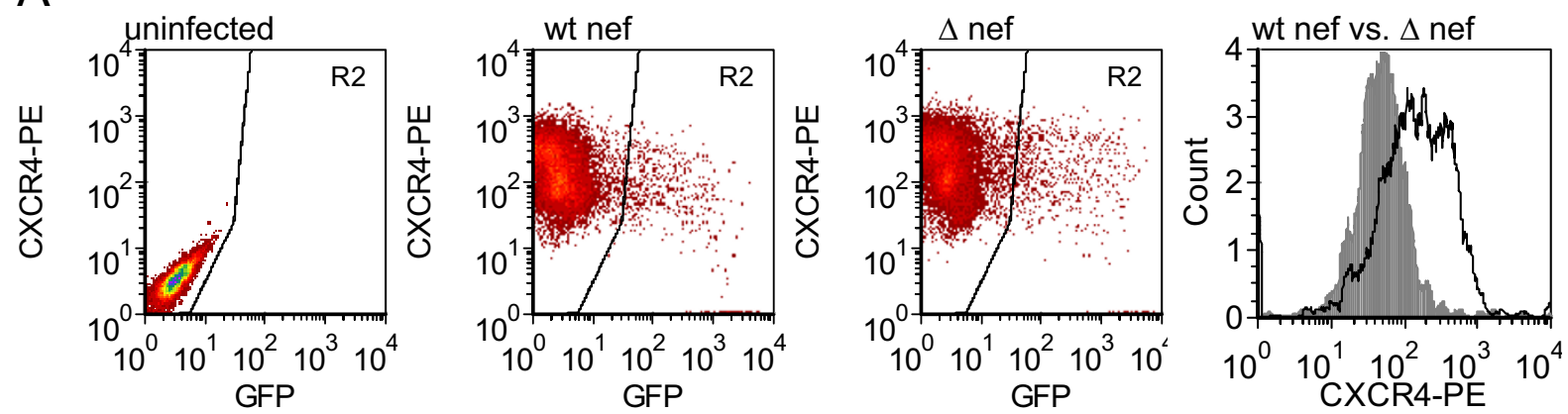

B
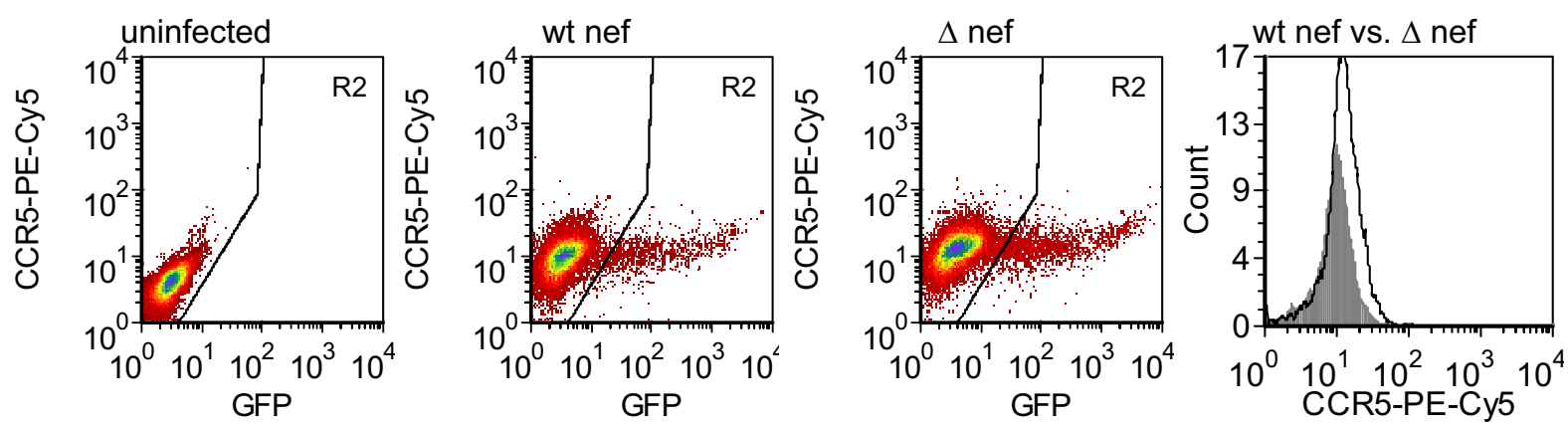

C

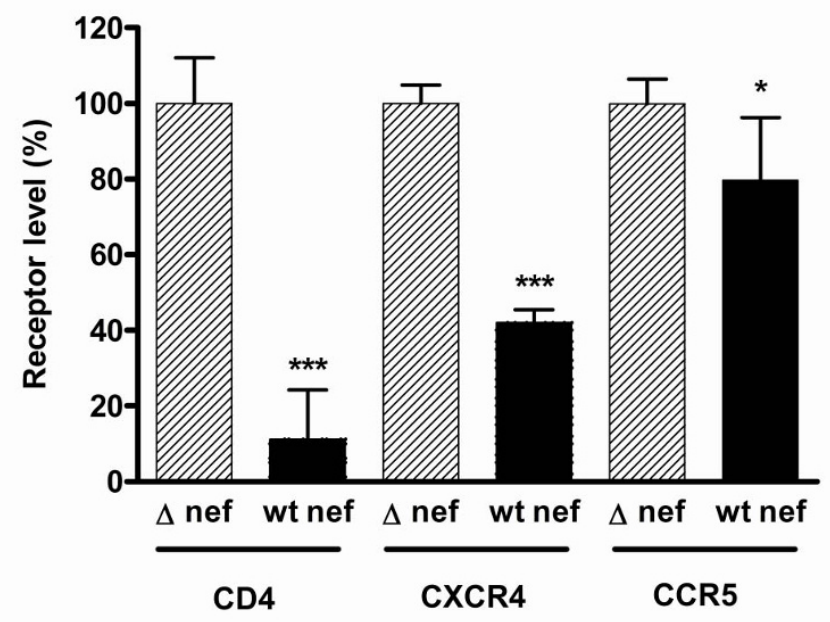

Figure 3 Nef-mediated downregulation of cell surface CXCR4, CCR5 and CD4 by integrase-deficient (D116N) virus. A. Flow cytometry dot plots demonstrating analysis of GFP positive cells in gate R2, depicting cells infected with integrase-deficient D1 16N virus. Cells infected with integrase deficient virus bearing the $\triangle$-nefmutation demonstrate higher expression of CXCR4 than cells infected with wt nef virus. The histogram shows a direct comparison of CXCR4 levels for wt nefvirus (shaded grey) and $\triangle$-nef virus (black line, white background). B. Cells infected with integrase-deficient virus bearing the $\Delta$-nef mutation demonstrate higher levels of expression of CCR5 than those infected by wt nef virus. The histogram shows a direct comparison of CCR5 levels after infection by wt nef virus (shaded grey) vs. $\Delta$-nef virus (black line, white background). C. Cells infected with the integrasedeficient D116N virus were analyzed relative to uninfected cells for the presence of CD4, CXCR4 and CCR5 after infection with wt integrase virus containing either a wt nef or the $\Delta$-nef mutation. The geometric means of fluorescence for each receptor are expressed relative to $\Delta$-nef virus infection receptor levels. Results are from 3-5 independent experiments, each with two replicate infections. Error bars indicate standard deviations. For each receptor, statistical comparisons between wt nef and $\Delta$-nef virus were performed by two-tailed unpaired $t$-tests, $p<0.001\left(^{* * *}\right), p<0.05(*)$. 

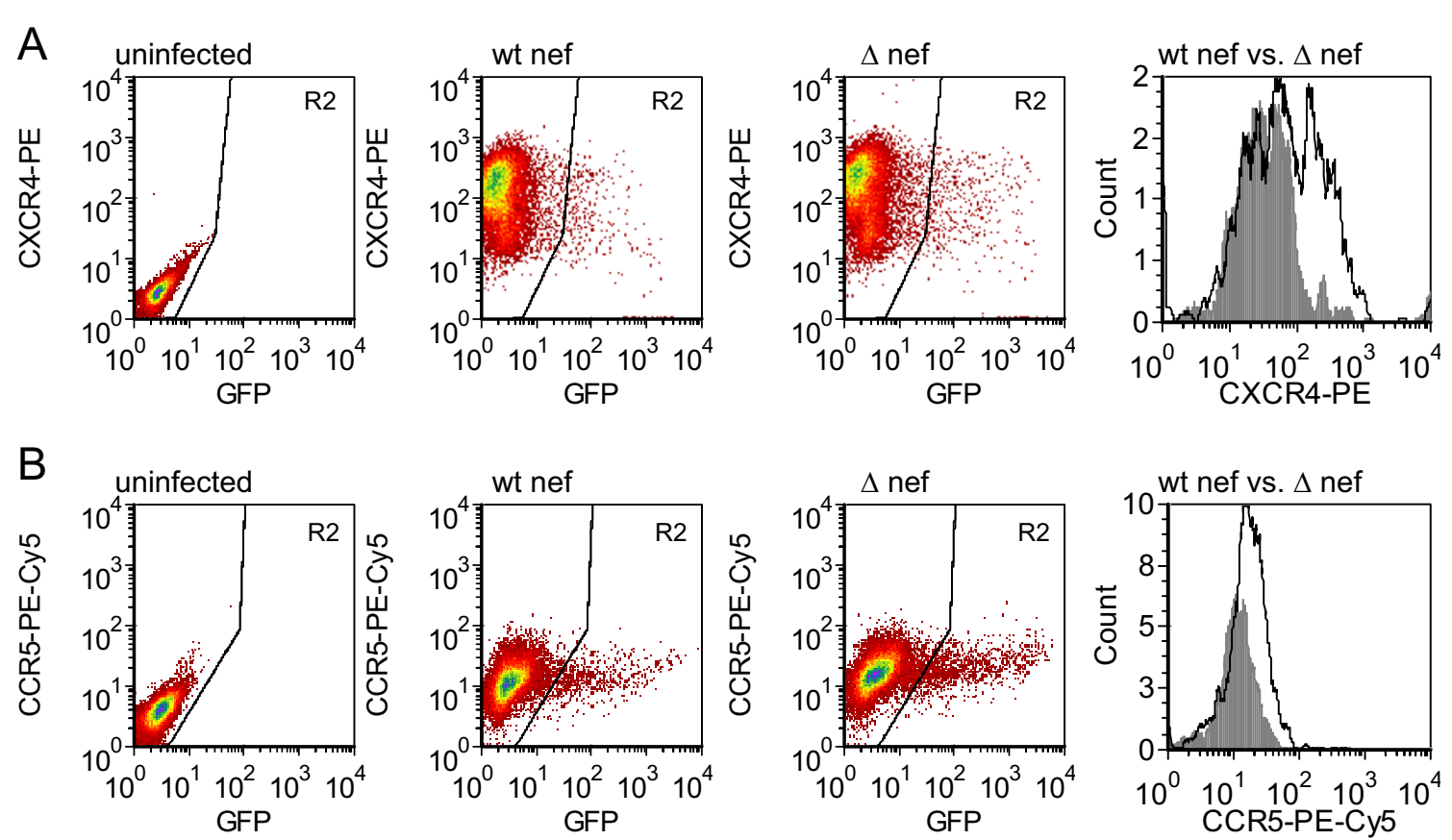

C
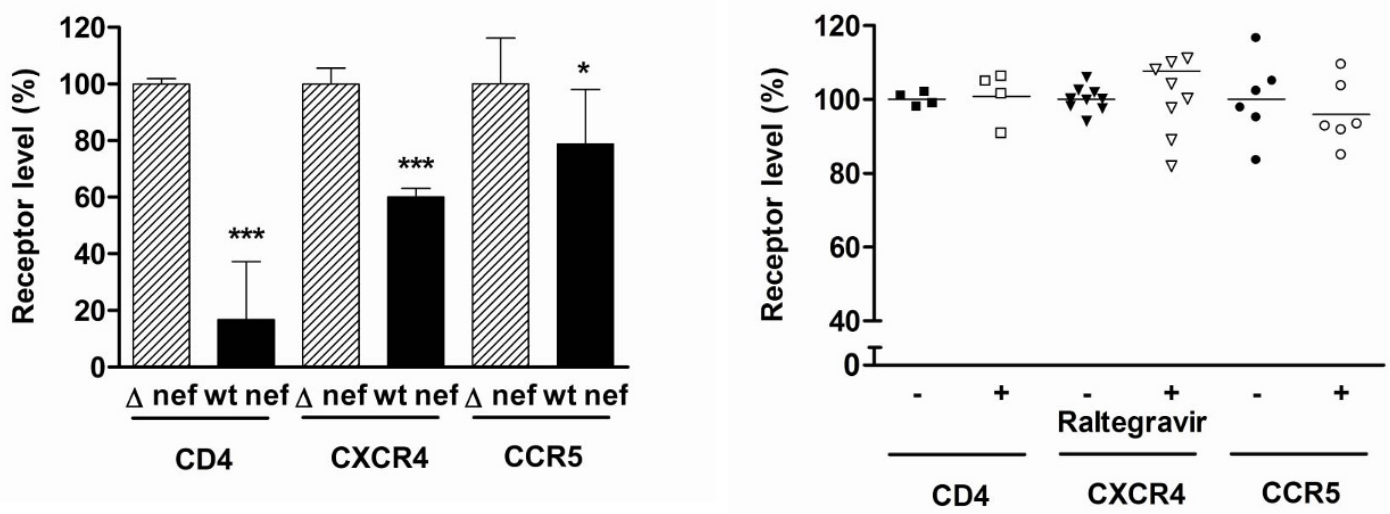

Figure 4 Nef-mediated downregulation of cell surface CXCR4, CCR5 and CD4 by IV-1 infection in the presence of raltegravir. A. FACs plots demonstrating analysis of cells infected with wt integrase virus in the presence of $1 \mu \mathrm{M}$ raltegravir. GFP-positive (infected) cells are depicted in gate R2. Cells infected with $\triangle$-nef virus demonstrate higher expression of CXCR4 than occurs for wt nef virus. The histogram shows a direct comparison of CXCR4 levels for wt nef virus (shaded grey) vs. $\Delta$-nefvirus (black line, white background). B. Cells infected with $\Delta$-nef virus in the presence of $1 \mu M$ raltegravir demonstrate higher-level expression of CCR5 than cells infected by wt nef virus. The histogram shows a direct comparison of CCR5 levels for wild-type nef virus (shaded grey) vs. $\Delta$-nef virus (black line, white background). C. Cells infected with wt virus containing either a wt nef or the $\Delta$-nef mutation in the presence of raltegravir were analyzed relative to uninfected cells for the presence of cell surface CD4, CXCR4 and CCR5. Geometric means of fluorescence for each receptor are expressed relative to infection by the $\Delta$-nef virus. Results are from 3-5 independent experiments, each performed in duplicate. Error bars indicate standard deviations. For each receptor, statistical comparisons between wt nefand $\Delta$-nefviruses were made by two-tailed unpaired $t$-tests, $p<0.001\left(^{* * *}\right), p<0.05\left(^{*}\right)$. D. $1 \mu \mathrm{M}$ raltegravir does not directly influence cell surface levels of CD4, CXCR4 and CCR5. Uninfected cells were treated in the presence or absence of $1 \mu \mathrm{M}$ raltegravir and then stained for CD4, CXCR4 or CCR4. Plots display expression levels relative to untreated cells. Results are from 3-5 independent experiments, each performed in duplicate. For each receptor, statistical comparisons between untreated and treated cells were made by two-tailed unpaired $t$-tests. No statistically significant differences were found. 
lation of CCR 5 seen with integrated infections of TZM/bl cells [36]. Studies with 293-Affinofile cells, a cell line that is quantitatively inducible for both CD4 and CCR5 cell surface expression, revealed that even modest downregulation of CCR5 from the cell surface was sufficient to impact infectibility, particularly in the context of reduced CD4 levels [41-43]. In our system as well, the levels of downregulation of CCR5 and CD4 that we report can probably limit viral entry.

With our methodology, one would not expect that Env would contribute to receptor downregulation, as we used env deleted pseudovirus bearing a VSV-G envelope. Additionally, although Vpu can act to downregulate CD4, there is currently no evidence that Vpu can modulate levels of CXCR4 and CCR5. Further, Vpu is not synthesized from unintegrated cDNA, and is therefore unlikely to affect cell surface CD4 levels.

An important consideration is that patterns of transcription and translation from unintegrated virus, arising from D116N integrase mutations or INSTI-treated cells, are identical to those observed in infections of quiescent $\mathrm{T}$-cells prior to integration [13]. Further, there are insufficient levels of 2-LTR circles in integrase-deficient infections of Rev-CEM cells to account for the numbers of transcriptionally active cells, the inference being that unintegrated linear cDNA molecules, rather than 2-LTR circles, are the likely template for transcription [20]. Thus, blockage of integration can be informative in regard to transcription from linear cDNAs. Slowly replicating cells such as resting T-cells $[13,44]$ and non-replicating cells such as macrophages [12] display a lag in transcription prior to integration. Cells in this state comprise the pre-integration latent reservoir [45]; and transcription during this period may be beneficial in regard to restricting superinfection, that may in turn be deleterious for cell viability and hence the likelihood of productive infection $[37,38]$. Rev can regulate integration [46] and, in addition, Rev generated from unintegrated DNA can act to restrict superinfection [47]. Downregulation of entry receptors may provide similar benefit, as is also seen with integrating infections $[34,36]$. Of course, recombination between unintegrated DNA and superinfecting virus might still occur as has been observed in vitro $[48,49]$.

Downregulation of coreceptors by unintegrated DNA may also reduce cell-signaling due to stimulation by natural ligands or viral envelope. This may help to avert adverse effects such as chemotaxis, apoptosis, and changes in viral transcription [50-54]. Further, there may be an immunological benefit for Nef-mediated downregulation of MHC-I by unintegrated DNA, which may result in evasion from cytotoxic T-cell mediated lysis [55].

In summary, we have provided further evidence that Nef translation from unintegrated DNA can occur at functionally relevant levels, and leads to reduced cell surface expression of CXCR4 and CCR5 as well as CD4. Additional work to determine the benefits of coreceptor downregulation for virus-infected cells is now in progress.

\section{Methods}

\section{Plasmids and cloning}

The HIV-1 molecular clone pNL4-3 was altered through site-directed mutagenesis (Stratagene) to introduce termination codons in the first and third amino acids of the env gene (construct termed pNL4-3- $\Delta \mathrm{E}$ ). Further modifications by mutagenesis included the substitution D116N in the integrase coding sequence of the pol gene (construct termed pNL4-3- $\Delta \mathrm{E}-\mathrm{D} 116 \mathrm{~N}$ ) and the introduction of termination codons into the first and third codons of the nef gene (constructs termed pNL4-3- $\Delta \mathrm{E}-\Delta \mathrm{N}$ and pNL4-3-D116N- $\Delta \mathrm{E}-\Delta \mathrm{N}$ ).

\section{Virus production}

Pseudovirus was produced by cotransfection via lipofectamine (Invitrogen) of $7 \times 10^{6} 293 \mathrm{~T}$ cells with $4 \mu \mathrm{g}$ pVPack-VSV-G (Stratagene), a vesicular stomatitis virus G protein (VSV-G) envelope-encoding construct, in combination with $12 \mu \mathrm{g}$ of a pNL4-3 derivative (either pNL43- $\Delta \mathrm{E}$, pNL4-3-D116N $\Delta \mathrm{E}$, pNL4-3- $\Delta \mathrm{E}-\Delta \mathrm{N}$ or pNL4-3$\mathrm{D} 116 \mathrm{~N}-\Delta \mathrm{E}-\Delta \mathrm{N})$.

All transfection supernatants were harvested at $72 \mathrm{~h}$ post transfection, clarified by centrifugation for $5 \mathrm{~min}$ at $470 \mathrm{~g}$, and passed through a $0.45 \mu \mathrm{m}$ filter. Virus was treated with $50 \mathrm{U} / \mathrm{ml}$ benzonase at $37^{\circ} \mathrm{C}$ for 20 minutes to digest contaminating plasmid DNA [56] and then stored at $-80^{\circ} \mathrm{C}$ until use.

\section{Cell culture and viral infections}

CXCR4-and CCR5 bearing Rev-CEM cells [19] were obtained through the NIH AIDS Research and Reference Reagent Program (courtesy of Professor Yuntao $\mathrm{Wu}$ ) and were maintained in RPMI 1640 medium (Invitrogen), and 293T cells were maintained in DMEM (Invitrogen), each supplemented with $10 \%$ fetal bovine serum, $1 \%$ L-glutamine and $1 \%$ penicillin/streptomycin.

$1.25 \times 10^{5} \mathrm{Rev}$-CEM cells were infected with $500 \mathrm{ng}$ p 24 of virus in 24 well plates by spinoculation at $1200 \mathrm{~g}$ at $25^{\circ} \mathrm{C}$ for $2 \mathrm{~h}$ followed by $2 \mathrm{~h}$ at $37^{\circ} \mathrm{C}$, after which medium was replaced, resulting in a multiplicity of infection (MOI) of 0.1 for wt virus as determined by GFP expression. Cells were infected with wt nef or $\Delta$-nef virus that was either integrase competent (wt) or that contained a defective D116N mutated integrase. Additional infections were performed with wt integrase-containing pseudoviruses. In some cases, media were pre-treated with $1 \mu \mathrm{M}$ final concentration raltegravir (a gift from Merck Canada, Inc) for $1 \mathrm{~h}$ prior to infection; after spinoculation, ralte- 
gravir-containing media were again used at a concentration of $1 \mu \mathrm{M}$.

\section{Integrated DNA qPCR}

For the integrated DNA qPCR assays, cellular DNA was extracted with a DNeasy blood and tissue kit (Qiagen). PCR was performed with Platinum qPCR SuperMixUDG (Invitrogen) on a Corbett Rotor-Gene 6000 thermocycler.

A previously described Alu-gag PCR analysis was used [57] with the following modifications [58]. The first round reaction was performed on undiluted samples (100 ng template) and 1:10 dilutions of each sample (10 ng template diluted with uninfected DNA; 100 ng DNA total) in the presence of $2 \mathrm{mM} \mathrm{MgCl}_{2}$ and $200 \mu \mathrm{M} \mathrm{dNTPs}$. $9 \mu \mathrm{l}$ of the resulting first round product were used as template for the second round nested reaction in the presence of $5 \mathrm{mM} \mathrm{MgCl} 2$ (final concentration including $\mathrm{MgCl}_{2}$ carryover from first round) and $200 \mu \mathrm{M}$ dNTPs, using the "wild-type" probe only. Second round cycling conditions were $50^{\circ} \mathrm{C}$ for $2 \mathrm{~min}, 95^{\circ} \mathrm{C}$ for $1 \mathrm{~min}$, and 45 cycles of $95^{\circ} \mathrm{C}$ for $15 \mathrm{sec}$ and $60^{\circ} \mathrm{C}$ for $30 \mathrm{sec}$. Dual-labeled probes were obtained from Biosearch Technologies (Novato, CA, USA). To generate a standard curve for relative quantification of integrated DNA, Alu-gag PCR was first performed on a dilution series of DNA from infected Rev-CEM cells (diluted with DNA from uninfected cells).

\section{Western Blot}

$2 \times 10^{5}$ Rev-CEM cells were infected with pNL4-3- $\Delta \mathrm{E}$, pNL4-3-D116N $\Delta \mathrm{E}$, pNL4-3- $\Delta \mathrm{E}-\Delta \mathrm{N}$ or pNL4-3-D116N$\Delta \mathrm{E}-\Delta \mathrm{N}$, in the presence or absence of raltegravir. The cells were collected after 72 hours and pelleted by low speed centrifugation at $470 \mathrm{~g}$. The pellet was resuspended in RIPA buffer $(0.15 \mathrm{M} \mathrm{NaCl}, 20 \mathrm{mM}$ Tris pH 7.4, $2 \mathrm{mM}$ EDTA, $1 \%$ Triton X-100 and 1\% deoxycholate). Cell lysates were normalized by Bradford assay to $1 \mathrm{mg} / \mathrm{ml}$ total protein and resolved in a $12 \%$ SDS-PAGE gel. The blot was incubated for 60 minutes with 1:4000 polyclonal anti-HIV-1 Nef antibody obtained from the NIH AIDS Research and Reference Reagent Program (catalog number 2949) and anti-rabbit IgG AP conjugate (secondary antibody) $(1: 10,000)$. A chemoluminescent reagent WestPico (Pierce) was used to develop the blots.

\section{Cell surface CXCR4, CCR5 and CD4 staining}

Rev-CEM cells that had been infected with pseudovirus were stained at $72 \mathrm{~h}$ post-infection in PBS containing 3\% fetal bovine serum and $0.05 \%$ sodium azide for $30 \mathrm{~min}$ utes at $4^{\circ} \mathrm{C}$ with the following mouse monoclonal antibodies (MAbs): allophycocyanin (APC)-conjugated antihuman CD4 (clone RPA-T4; BD PharMingen); phycoerythrin (PE)-conjugated anti-human CXCR4 MAb (clone 12G5; BD PharMingen); PE-Cy5-conjugated anti- human CCR5 MAb (clone 2D7 BD PharMingen). Cells were then fixed in a final concentration of $1 \%$ paraformaldehyde, and then resuspended in PBS containing 3\% fetal bovine serum and $0.05 \%$ sodium azide. 10,000 events were assayed on a FACSCalibur instrument (BD PharMingen); analysis was performed with BD CellQuest Pro 4.0.2 (BD PharMingen) and FCS Express 3 software (DeNovo). Levels of receptors were quantified relative to those found after infection by $\Delta$-nef virus. These studies were controlled for by subtracting background isotype fluorescence values from antibody-receptor fluorescence measurements.

\section{Statistical analysis}

All statistical analyses were performed with GraphPad Prism 4.0 software. To test for statistically significant differences between groups, unpaired two-tailed $t$-tests were performed with confidence intervals set at $95 \%$.

\section{Abbreviations}

INSTI: Integrase strand transfer inhibitor.

\section{Competing interests}

The authors declare that they have no competing interests.

\section{Authors' contributions}

RDS designed the study, performed the experiments and drafted the manuscript. DAD helped design the study and performed qPCR optimization. BDK helped with plasmid construction and flow cytometry analysis. TB-M performed Western blots and assisted in the study design. MAW provided overall supervision for the project, secured funding, and helped write the manuscript. All authors read and approved the final manuscript.

\section{Acknowledgements}

This work was supported by grants from the Canadian Institutes of Health Research (CIHR), and Merck Canada Inc. RDS is the recipient of a postdoctoral fellowship jointly funded by the CIHR Canadian HIV Trials Network (CTN) and the Canadian Foundation for AIDS Research (CANFAR). DAD is the recipient of a predoctoral fellowship from the Fonds de la Recherche en Santé du Québec (FRSQ).

We thank Daria Hazuda of Merck Inc. for helpful comments and Drs Yuntao Wu and Jon Marsh for the kind provision of the Rev-CEM cell line. We also thank Cesar Collazos and Susan Colby-Germinario of the McGill AIDS Centre and Christian Young of the Lady Davis Institute flow cytometry core facilities for providing valuable technical assistance.

\section{Author Details}

'McGill University AIDS Centre, Lady Davis Institute, Jewish General Hospital, Montréal, QC, Canada, ${ }^{2}$ Department of Microbiology and Immunology, McGill University, Montréal, QC, Canada and 'Department of Experimental Medicine, McGill University, Montréal, QC, Canada

Received: 17 March 2010 Accepted: 13 May 2010

Published: 13 May 2010

\section{References}

1. Chun T, Carruth L, Finzi D, Shen X, DiGiuseppe J, Taylor H, Hermankova M, Chadwick K, Margolick J, Quinn TC, Kuo YH, Brookmeyer R, Zeiger MA, Barditch-Crovo P, Siliciano RF: Quantification of latent tissue reservoirs and total body viral load in HIV-1 infection. Nature 1997, 387:183-188.

2. Pang S, Koyanagi $Y$, Miles S, Wiley C, Vinters $H$, Chen I: High levels of unintegrated HIV-1 DNA in brain tissue of AIDS dementia patients. Nature 1990, 343:85-89.

3. Sharkey M, Teo I, Greenough T, Sharova N, Luzuriaga K, Sullivan J, Bucy R, Kostrikis L, Haase A, Veryard C, Davaro RE, Cheeseman SH, Daly JS, Bova C, 
Ellison RT, Mady B, Lai KK, Moyle G, Nelson M, Gazzard B, Shaunak S, Stevenson M: Persistence of episomal HIV-1 infection intermediates in patients on highly active anti-retroviral therapy. Nat Med 2000, 6:76-81.

4. Teo I, Veryard C, Barnes H, An S, Jones M, Lantos P, Luthert P, Shaunak S: Circular forms of unintegrated human immunodeficiency virus type 1 DNA and high levels of viral protein expression: association with dementia and multinucleated giant cells in the brains of patients with AIDS. J Virol 1997, 71:2928-2933

5. Bukrinsky M, Stanwick T, Dempsey M, Stevenson M: Quiescent T lymphocytes as an inducible virus reservoir in HIV-1 infection. Science 1991, 254:423-427.

6. Farnet $C$, Haseltine $W$ : Circularization of human immunodeficiency virus type 1 DNA in vitro. J Virol 1991, 65:6942-6952.

7. Khiytani D, Dimmock N: Characterization of a human immunodeficiency virus type 1 pre-integration complex in which the majority of the cDNA is resistant to DNase I digestion. J Gen Virol 2002, 83:2523-2532.

8. Poon $B, C$ ang $M$, Chen I: Vpr is required for efficient Nef expression from unintegrated human immunodeficiency virus type 1 DNA. J Virol 2007, 81:10515-10523

9. Englund $G$, Theodore T, Freed E, Engelman A, Martin M: Integration is required for productive infection of monocyte-derived macrophages by human immunodeficiency virus type 1. J Virol 1995, 69:3216-3219.

10. Wiskerchen $M$, Muesing M: Human immunodeficiency virus type 1 integrase: effects of mutations on viral ability to integrate, direct viral gene expression from unintegrated viral DNA templates, and sustain viral propagation in primary cells. J Virol 1995, 69:376-386.

11. Wu Y, Marsh J: Early transcription from nonintegrated DNA in human immunodeficiency virus infection. J Virol 2003, 77:10376-10382.

12. Kelly J, Beddall M, Yu D, lyer S, Marsh J, Wu Y: Human macrophages support persistent transcription from unintegrated HIV-1 DNA. Virology 2008, 372:300-312.

13. Wu Y, Marsh J: Selective transcription and modulation of resting T cell activity by preintegrated HIV DNA. Science 2001, 293:1503-1506.

14. Gillim-Ross L, Cara A, Klotman M: Nef expressed from human immunodeficiency virus type 1 extrachromosomal DNA downregulates CD4 on primary CD4+ T lymphocytes: implications for integrase inhibitors. J Gen Virol 2005, 86:765-771.

15. Ansari-Lari M, Donehower L, Gibbs R: Analysis of human immunodeficiency virus type 1 integrase mutants. Virology 1995 211:332-335.

16. Stevenson M, Haggerty S, Lamonica C, Meier C, Welch S, Wasiak A: Integration is not necessary for expression of human immunodeficiency virus type 1 protein products. J Virol 1990, 64:2421-2425.

17. Engelman A, Englund G, Orenstein J, Martin M, Craigie R: Multiple effects of mutations in human immunodeficiency virus type 1 integrase on viral replication. J Virol 1995, 69:2729-2736.

18. Wu Y, Beddall M, Marsh J: Rev-dependent lentiviral expression vector. Retrovirology 2007, 4:12.

19. Wu Y, Beddall M, Marsh J: Rev-dependent indicator T cell line. Curr HIV Res 2007, 5:394-402

20. Iyer $S, Y u$ D, Biancotto A, Margolis L, Wu Y: Measurement of human immunodeficiency virus type 1 preintegration transcription by using Rev-dependent Rev-CEM cells reveals a sizable transcribing DNA population comparable to that from proviral templates. J Virol 2009, 83:8662-8673

21. Brussel A, Sonigo P: Evidence for gene expression by unintegrated human immunodeficiency virus type 1 DNA species. J Virol 2004, 78:11263-11271.

22. Poon B, Chen I: Human immunodeficiency virus type 1 (HIV-1) Vpr enhances expression from unintegrated HIV-1 DNA. J Virol 2003. 77:3962-3972

23. Butler S, Johnson E, Bushman F: Human immunodeficiency virus cDNA metabolism: notable stability of two-long terminal repeat circles. $J$ Virol 2002, 76:3739-3747

24. Pierson T, Kieffer T, Ruff C, Buck C, Gange S, Siliciano R: Intrinsic stability of episomal circles formed during human immunodeficiency virus type 1 replication. J Virol 2002, 76:4138-4144.

25. Vargas JJ, Gusella G, Najfeld V, Klotman M, Cara A: Novel integrasedefective lentiviral episomal vectors for gene transfer. Hum Gene Ther 2004, 15:361-372.
26. Lu R, Nakajima N, Hofmann W, Benkirane M, Jeang K, Sodroski J, Engelman A, Teh-Jeang K: Simian virus 40-based replication of catalytically inactive human immunodeficiency virus type 1 integrase mutants in nonpermissive T cells and monocyte-derived macrophages. J Virol 2004, 78:658-668

27. Mannioui A, Schiffer C, Felix N, Nelson E, Brussel A, Sonigo P, Gluckman J, Canque $B$ : Cell cycle regulation of human immunodeficiency virus type 1 integration in T cells: antagonistic effects of nuclear envelope breakdown and chromatin condensation. Virology 2004, 329:77-88.

28. Bushman F: Measuring covert HIV replication during HAART: the abundance of 2-LTR circles is not a reliable marker. AIDS 2003 17:749-750

29. Gillim-Ross L, Cara A, Klotman M: HIV-1 extrachromosomal 2-LTR circular DNA is long-lived in human macrophages. Viral Immunol 2005, 18:190-196.

30. Wu Y: The second chance story of HIV-1 DNA: Unintegrated? Not a problem! Retrovirology 2008, 5:61

31. Cara A, Klotman M: Retroviral E-DNA: persistence and gene expression in nondividing immune cells. J Leukoc Bio/ 2006, 80:1013-1017.

32. Hazuda D, Felock P, Witmer M, Wolfe A, Stillmock K, Grobler J, Espeseth A Gabryelski L, Schleif W, Blau C, Miller M: Inhibitors of strand transfer that prevent integration and inhibit HIV-1 replication in cells. Science 2000, 287:646-650.

33. Butler $\mathrm{S}$, Hansen M, Bushman F: A quantitative assay for HIV DNA integration in vivo. Nat Med 2001, 7:631-634.

34. Venzke S, Michel N, Allespach I, Fackler O, Keppler O: Expression of Nef downregulates CXCR4, the major coreceptor of human immunodeficiency virus, from the surfaces of target cells and thereby enhances resistance to superinfection. J Virol 2006, 80:11141-11152.

35. Wildum S, Schindler M, Münch J, Kirchhoff F: Contribution of Vpu, Env, and Nef to CD4 down-modulation and resistance of human immunodeficiency virus type 1-infected T cells to superinfection. $J$ Virol 2006, 80:8047-8059.

36. Michel N, Allespach I, Venzke S, Fackler O, Keppler O: The Nef protein of human immunodeficiency virus establishes superinfection immunity by a dual strategy to downregulate cell-surface CCR5 and CD4. Curr Biol 2005, 15:714-723.

37. Pauza C, Galindo J, Richman D: Reinfection results in accumulation of unintegrated viral DNA in cytopathic and persistent human immunodeficiency virus type 1 infection of CEM cells. J Exp Med 1990 172:1035-1042.

38. Robinson $\mathrm{H}$, Zinkus D: Accumulation of human immunodeficiency virus type 1 DNA in T cells: results of multiple infection events. J Virol 1990, 64:4836-4841.

39. Wu Y, Yoder A: Chemokine coreceptor signaling in HIV-1 infection and pathogenesis. PLoS Pathog 2009, 5:e1000520.

40. Lama J: The physiological relevance of CD4 receptor down-modulation during HIV infection. Curr HIV Res 2003, 1:167-184

41. Johnston S, Lobritz M, Nguyen S, Lassen K, Delair S, Posta F, Bryson Y, Arts $E$, Chou T, Lee B: A quantitative affinity-profiling system that reveals distinct CD4/CCR5 usage patterns among human immunodeficiency virus type 1 and simian immunodeficiency virus strains. J Virol 2009, 83:11016-11026.

42. Lassen K, Lobritz M, Bailey J, Johnston S, Nguyen S, Lee B, Chou T, Siliciano R, Markowitz M, Arts E: Elite suppressor-derived HIV-1 envelope glycoproteins exhibit reduced entry efficiency and kinetics. PLOS Pathog 2009, 5:e1000377.

43. Pugach P, Ray N, Klasse P, Ketas T, Michael E, Doms R, Lee B, Moore J: Inefficient entry of vicriviroc-resistant HIV-1 via the inhibitor-CCR5 complex at low cell surface CCR5 densities. Virology 2009, 387:296-302.

44. Pierson T, Zhou Y, Kieffer T, Ruff C, Buck C, Siliciano R: Molecular characterization of preintegration latency in human immunodeficiency virus type 1 infection. J Virol 2002, 76:8518-8531.

45. Petitjean G, AI Tabaa Y, Tuaillon E, Mettling C, Baillat V, Reynes J, Segondy $M$, Vendrell J: Unintegrated HIV-1 provides an inducible and functional reservoir in untreated and highly active antiretroviral therapy-treated patients. Retrovirology 2007, 4:60.

46. Levin A, Rosenbluh J, Hayouka Z, Friedler A, Loyter A: Integration of HIV-1 DNA is regulated by interplay between viral rev and cellular LEDGF/ p75 proteins. Mol Med 16:34-44. 
47. Levin A, Hayouka Z, Friedler A, Brack-Werner R, Volsky D, Loyter A: A novel role for the viral Rev protein in promoting resistance to Super-infection by Human Immunodeficiency Virus type 1. J Gen Virol 2010 in press.

48. Gelderblom H, Vatakis D, Burke S, Lawrie S, Bristol G, Levy D: Viral complementation allows HIV-1 replication without integration. Retrovirology 2008, 5:60.

49. Quan Y, Liang C, Brenner B, Wainberg M: Multidrug-resistant variants of HIV type 1 (HIV-1) can exist in cells as defective quasispecies and be rescued by superinfection with other defective HIV-1 variants. J Infect Dis 2009, 200:1479-1483.

50. Khan M, Brandimarti R, Patel J, Huynh N, Wang J, Huang Z, Fatatis A, Meucci O: Apoptotic and antiapoptotic effects of CXCR4: is it a matter of intrinsic efficacy? Implications for HIV neuropathogenesis. AIDS Res Hum Retroviruses 2004, 20:1063-1071.

51. Cocchi F, DeVico A, Garzino-Demo A, Arya S, Gallo R, Lusso P: Identification of RANTES, MIP-1 alpha, and MIP-1 beta as the major HIVsuppressive factors produced by CD8+ T cells. Science 1995, 270:1811-1815.

52. Davis C, Dikic I, Unutmaz D, Hill C, Arthos J, Siani M, Thompson D, Schlessinger J, Littman D: Signal transduction due to HIV-1 envelope interactions with chemokine receptors CXCR4 or CCR5. J Exp Med 1997, 186:1793-1798.

53. Zaitseva M, Peden K, Golding H: HIV coreceptors: role of structure, posttranslational modifications, and internalization in viral-cell fusion and as targets for entry inhibitors. Biochim Biophys Acta 2003, 1614:51-61.

54. Tremblay M, Meloche S, Gratton S, Wainberg M, Sékaly R: Association of p56lck with the cytoplasmic domain of CD4 modulates HIV-1 expression. EMBO J 1994, 13:774-783.

55. Collins K, Chen B, Kalams S, Walker B, Baltimore D: HIV-1 Nef protein protects infected primary cells against killing by cytotoxic $T$ lymphocytes. Nature 1998, 391:397-401.

56. Sastry L, Xu Y, Cooper R, Pollok K, Cornetta K: Evaluation of plasmid DNA removal from lentiviral vectors by benzonase treatment. Hum Gene Ther 2004, 15:221-226.

57. Yu J, Wu T, Liszewski M, Dai J, Swiggard W, Baytop C, Frank I, Levine B, Yang W, Theodosopoulos T, O'Doherty U: A more precise HIV integration assay designed to detect small differences finds lower levels of integrated DNA in HAART treated patients. Virology 2008, 379:78-86.

58. Donahue D, Sloan R, Kuhl B, Bar-Magen T, Schader S, Wainberg M: StageDependent Inhibition of HIV-1 Replication by Antiretroviral Drugs in Cell Culture. Antimicrob Agents Chemother 2009, 54:1047-1054.

doi: $10.1186 / 1742-4690-7-44$

Cite this article as: Sloan et al., Expression of Nef from unintegrated HIV-1 DNA downregulates cell surface CXCR4 and CCR5 on T-lymphocytes Retrovirology 2010, 7:44

\section{Submit your next manuscript to BioMed Centra} and take full advantage of:

- Convenient online submission

- Thorough peer review

- No space constraints or color figure charges

- Immediate publication on acceptance

- Inclusion in PubMed, CAS, Scopus and Google Scholar

- Research which is freely available for redistribution

Submit your manuscript at www.biomedcentral.com/submit
Ciomed Central 